\title{
Subgroups of attributional profiles in students with learning difficulties and their relation to self-concept and academic goals
}

\author{
José Carlos Núñez ${ }^{1}$, Julio A. González-Pienda ${ }^{1}$, Soledad González-Pumariega ${ }^{1}$, \\ Cristina Roces ${ }^{1}$, Luis Álvarez ${ }^{1}$, Paloma González ${ }^{1}$, Ramón G. Cabanach ${ }^{2}$, Antonio \\ Valle $^{2}$, and Susana Rodríguez ${ }^{2}$ \\ ${ }^{1}$ University of Oviedo \\ ${ }^{2}$ University of A Coruña
}

\begin{abstract}
The aim of this article was fourfold: first, to determine whether there are significant differences between students with $(N=173)$ and without learning disabilities $(\mathrm{LD} ; N=172)$ in the dimensions of self-concept, causal attributions, and academic goals. Second, to determine whether students with LD present a uniform attributional profile or whether there are subgroups of attributional profiles among students with LD. Third, to explore differences between these profiles on the dimensions of self-concept, academic goals, perception of competence-incompetence, persistence when faced with failure, peer relationships, and academic achievement. Fourth, to determine whether there are significant differences in the dimensions of self-concept and academic goals between NLD students and the different LD subgroups. The results indicate the existence of two very distinct attributional profiles in students with LD (Helplessness Profile and Adaptive Profile). The implications of these data with regard to theory and research, as well as educational practice, are discussed.
\end{abstract}


Current theory and research indicate that self-concept, adaptive causal attributions, and motivation (along with strategic knowledge) are crucial for effective metacognitive processing (González-Pienda et al., 2002; Pintrich, 2000). However, after more than 30 years of research on the motivational and affective sphere of students with learning disabilities (LD), and its relation to school learning, instead of a unified panorama, we find an enormous quantity of contradictory results (Gresham \& MacMillan, 1997). Although one could infer from most of the studies that students with LD, compared to their peers without LD (NLD), have a more negative self- concept, less motivation to learn, and a maladaptive attributional profile, the data provided by more recent investigations suggest that not all students with LD have the same profile. In the following paragraphs, we describe the scope of the discrepancy in the results of past research and provide a rationale for the present study.

\section{Causal Attributions}

The attributional theory proposed by Bernard Weiner ex- plains motivation as a function of an individual's perceptions of the causes of previous successes and failures (Weiner, 2000). A large part of the research performed within this paradigm in the field of special education indicates that students with LD feel threatened by failure and usually attribute their successes to external variables such as luck, others' help, etc., and their failures to the lack of ability (more than to insufficient effort). Thus, an important portion of the research carried out to date has concluded that children or adolescents with LD tend to manifest a maladaptive attributional style, low achievement expectations, low persistence at school tasks, and low academic self-concept (Kirk \& Gallagher, 1986; Montgomery, 1994; Núñez, González- Pumariega, \& González-Pienda, 1995). In turn, these attitudes reduce student motivation and generate negative feelings about their academic work and about themselves. With time, this cycle of reciprocal interactions generates a strong sense of learned helplessness (Chapman, 1988) in these children. Among other aspects, the state of helplessness is characterized by the belief that academic failures are caused by personal deficits (i.e., "lack of ability") and that successes are due to the concurrence of external factors (i.e., "luck," "easy task," "help of others") beyond the children's control (Licht \& Kistner, 1986). This state of helplessness may ultimately lead to a situation of depression or hopelessness in these students, characterized by the belief that, no matter how much effort they make, they are doomed to fail (Smiley \& Dweck, 1994). Because of its negative motivational consequences, this kind of attributional profile has been called a "maladaptive attributional profile" by some authors, or also a "pessimistic explanatory style" (Seligman, 1990).

However, despite the fact that many authors report data supporting the existence of an inadequate motivational- affective profile, both in children and in adolescents with LD, the results of some studies indicate that not all children with LD present maladaptive attributional profiles (i.e., Durrant, 1993; González-Pienda et al., 2000; Jackobsen et al., 1986).

\section{Self-Concept}

The self-concept of students with LD is one of the variables that has received the most attention within the areas of affect and motivation. However, reports by the researchers do not all point in the same direction. Thus, whereas one group of studies has shown that students with LD presented lower ability and achievement expectations than their counterparts without LD (Bear, Juvonen, \& McInerney, 1993; Chapman, 1988; Gans, Kenny, \& Ghany, 2003; González-Pienda et al., 2000; Grolnick \& Ryan, 1990; Harter, Whitesell, \& Junkin, 1998; Kloomok \& Cosden, 1994; Núñez et al., 1995; Rogers \& Saklofske, 1985; Stone \& May, 2002; Valas, 1999; Vaughn, Elbaum, Schumm, \& Hughes, 1998; Vaughn, Haager, Hogan, \&Kouzekanani, 1992), another group of studies found no differences in academic self-concept between students with and without LD (Bear \& Minke, 1996; Bear, Minke, Griffin, \& Deemer, 1998; Dyson, 2003; Meltzer \& Montague, 2001; Meltzer, Roditi, Houser, \& Perlman, 1998; Montague \& van Garderen, 2003; Pintrich, Anderman, \& Klobucar, 1994; Priel \& Leshem, 1990). With regard to general self-concept, the data provided by past research are more concurrent. Specifically, McPhail and Stone (1995) have reviewed the most relevant studies and have presented data indicating that students with LD generally show positive general self- concepts and perceive themselves to be as capable as their 
peers (e.g., Bear, Clever, \& Proctor, 1991; Bear et al., 1993; Dyson, 2003; Gans et al., 2003; Harter et al., 1998; Nowicki, 2003; Sabornie, 1994; Stone \& May, 2002; Valas, 1999).

Researchers have formulated various explanations for these apparently contradictory data regarding academic self- concept. The most frequently proposed hypotheses were the following: (1) students with LD make unrealistic assessments of their abilities because of metacognitive deficits that limit their capacity to reflect upon their own abilities (Montague \& van Garderen, 2003; Stone \& May, 2002); (2) perception of social acceptance and favorable feedback by others (teachers, parents, friends); (3) lack of effort and engagement in school tasks, which allows these students to attribute failures to lack of effort (Bear et al., 1991; Kloomok \& Cosden, 1994); and (4) the development of disruptive behaviors as a way to avoid questioning one's own ability (Covington, 1998). On the other hand, it also seems reasonable to consider as explanatory factors the special importance of, among others, the type of instructional process followed in the classroom (general tasks vs. adapted tasks, normative evaluation vs. criterial evaluation, teachercentered classroom vs. learner-centered classroom, different disciplinary domains, etc.; Schuh, 2003; Stone, 2002), and the place where the student with LD receives instruction (full time in an ordinary classroom, in an ordinary classroom with support, mainly in an ordinary class- room with external support, in a special education classroom; Bakker \& Bosman, 2003). However, the data about this latter point do not seem very consistent because, for example, Elbaum (2002, pp. 221222) reported results that indicate that, in general, "there is no systematic association between the self-concept of students with LD and their educational placement"; although this author also acknowledged that "the finding of no reliable differences between groups of students with LD in different placements does not imply that there are no differences between any or all groups of students with LD and their peers without disabilities" (Elbaum, 2002, p. 224).

From our viewpoint, one could add to these explanations the hypothesis of the existence of different attributional pro- files within the group of students with LD (Núñez et al., 2002), and their relation with the level of global and academic self-concept, as well as the salient type of academic goal (e.g., learning, increasing competence, avoiding failure, etc.).

\section{Academic Goals}

Students' academic goals have been found to determine their affective, cognitive, and behavioral reactions to success or failure, in addition to the quality of their performance (Ames, 1992; Dweck, Chiu, \& Hong, 1995). Among the personal factors that determine motivational orientation are relevant causal attributions and academic self-concept. One of the features of learning-goal-oriented students is their belief that effort is the main cause of their academic results and that ability is a modifiable characteristic that depends on effort. For these individuals, more effort usually results in improved learning, and, consequently, they become more competent in that related knowledge area. In these circumstances, causal attributions to high levels of effort lead to high perceived competence. Therefore, effort-ability relations and perceptions of control and personal responsibility for academic results (all associated with internal attributional profile) contribute positively to the development of learning-oriented motivation. In addition, we must consider the decisive role of affective variables and self-perceptions and beliefs regarding academic level (academic self-concept). It is also evident that past academic achievement is one of the most influential factors in academic self-concept and in high self-confidence.

However, to date, there has been very little focus on the relation between causal attribution processes, academic goals, and self-concept in students with LD. This may be because, for a student with LD, it does not seem reasonable to feel attracted to learning goals; in any case, these students are preferably oriented to avoiding failure. 


\section{Summary and Objectives}

The results of psychological research reviewed do not allow drawing definitive conclusions about characteristic attributional and motivational profiles and self-concept in children or adolescents with LD. In this article, we present the results of an in-depth investigation of this seemingly confusing situation concerning self-concept, attributional profile, and motivational profile of students with LD. This investigation had four aims.

First, we wished to determine whether there were significant differences between students with and without LD with regard to the different dimensions of self-concept, causal attributions, and academic goals. Second, we wanted to know whether students with LD present a uniform attributional pro- file (maladaptive attributional profile) or whether, as some researchers indicate, there are various attributional profiles among students with LD. Third, if the existence of various attributional profiles were confirmed, we would undertake the analysis of the differences between subgroups on the dimensions of self-concept, academic goals, perception of competenceincompetence, persistence when faced with failure, peer relationships, and academic achievement. Fourth, if there were significant differences in self-concept and academic goals among the subgroups of students with LD, we would verify the first aim once again (i.e., are there significant differences in the dimensions of self-concept and academic goals among NLD students and each subgroup of students with LD?). This last aim was formulated to evaluate the ex- tent to which individual differences in the processes of causal attribution may account for the fact that some studies have found differences in self-concept, whereas other investigations have not.

\section{METHOD}

\section{Participants}

The selection of students with LD was made employing the minimum criteria established by Rosenberg et al. (1993). In- formation is provided about other relevant aspects. The total group of participants in this investigation was made up of 345 participants: 173 students with LD, ages 9 to 14 years $(M=12.28$ years, $S D=1.48 ; 117$ boys and 56 girls $)$ and 172 students without $L D$, ages 9 to 12 years $(M=10.60$ years, $S D=0.98 ; 100$ boys and 72 girls). Within the LD group, there were 6 nine-year-olds, 19 ten-year-olds, 27 eleven- year-olds, 39 twelve-year-olds, 32 thirteen-yearolds, and 50 fourteen-year-olds. In the group without LD, there were 26 nine-year-olds, 53 tenyear-olds, 57 eleven-year-olds, and 36 twelve-year-olds

The diagnosis performed by the school district specialists (integrated in psychopedagogical teams) was used to select the students with LD. The diagnostic process used at the public educational centers in Spain is described below.

Once the ordinary classroom teacher detects a student with poor performance with no apparent justification (e.g., motivational problems, discipline, etc.), the specialist of the psychopedagogical team addresses the magnitude of the learning delay, determining whether the student's academic performance is significantly lower than his/her intellectual ability. The discrepancy is considered significant when performance is 2 or more years lower than the general intellectual ability. Second, in the absence of some general intellectual deficit and in the presence of a significant discrepancy between intellectual abilities and performance, the specialist looks for a deficit in basic cognitive processes that would justify the discrepancy. Third, the specialist attempts to rule out the possibility that the existing learning problems are due to disabilities other from LDs (e.g., visual, auditive, motor, emotional, etc.). Finally, once the first three steps have been completed and considering the students as "potentially LDs" taking into account his/her characteristics (deficiencies and abilities), the specialist carries out modifications in the conditions of access to the curriculum that seem to be preventing the student from pursuing the ordinary curriculum normally. If the student does not respond to the adaptations, then the specialist, in collaboration with tutors, proceeds to carry out an "individual curricular adaptation" (ICA), which means that the student is assumed to be incapable of following the curriculum, at least at the established requirement level, and, as a result, the curriculum must be significantly modified. The adaptation is generally carried out over 2 years. Except for severe cases, the student receives instruction 
regarding the curriculum adapted to the ordinary classroom and also participates in supplemental instruction specific to his/her deficit or deficits, outside of the normal classroom.

The students in the present study had been diagnosed as having LD for an average period of almost 3 years $(M=31.81$ months). It is noted that this information (time interval since the student was diagnosed as having LD) was provided for only 85 students out of the total sample of students with LD. Regarding the students' specific deficits in the various academic areas, 79.2 percent were deficient in mathematics, 78.8 percent in language in general, and more concretely, 44.1 percent in reading-writing, 20.7 percent in social sciences, and 19.9 percent in natural sciences. On the other hand, 26.6 percent of these students with LD also presented significant behavior problems, and 14.5 percent showed deficits in emotional areas. The scores obtained in the Weschler Intelligence Scale for Children-Revised (WISC-R) were within the normal range for the full scale $(M=88.77$, $S D=6.80)$, on the verbal scale $(M=84.17, S D=7.78)$, and on the performance scale $(M=94.01$, $S D=8.22)$. The general academic achievement of the two student groups was compared using teacher ratings of overall achievement for the NLD students and overall achievement in academic areas in which no deficits were observed for the students with LD. An ANOVA revealed statistically significant differences between the two groups, $F(1,343)=143.04, p<0.001$ (LD: $M$ $=1.57, S D=0.68 ;$ NLD: $M=2.55, S D=0.84)$.

The tutors completed the General Learning Differences Questionnaire (see below) in order to provide information about the students with LD: (1) degree of persistence follow- ing failure, (2) the student's feelings about him- or herself as a student with LD, and (3) peers' behavior toward stu- dents with LD. Regarding persistence, the teachers reported that following failure, 18.5 percent desisted at first attempt, 36.4 percent desisted after a few attempts, 44.5 percent of the students asked for help after several attempts, and only 0.6 percent never desisted. Regarding their feelings, 30.7 per- cent of the students with LD felt incompetent or somewhat inferior to others, 48.6 percent were not particularly concerned, and 20.7 percent considered themselves to be as capable as the other students. Lastly, the teachers noted that, whereas 4.6 percent of the students with LD were treated scornfully by their peers and 10.9 percent were ignored, 82.1 percent were treated normally, and 2.4 percent were overprotected.

The LD participants were Caucasian, with the exception of one student who belonged to the Gypsy ethnic group. All the children without LD were Caucasian. The socioeconomic level of the families of both groups was between medium and low. The educational level of the families was mainly low (elementary studies). The schools attended by the participants were in urban and semiurban zones.

All the children with LD studied the same academic curriculum as their peers without LD. On the other hand, the students with LD received support in the normal classroom, which was reinforced by a special support class for 1 hour weekly. In some cases, they also received some other type of assistance such as attending special language education classes.

The selection of the sample of NLD students was carried out as follows. Once the students with LD from a specific classroom had been identified, a similar number of NLD peer students was randomly selected from the same classroom. This procedure allowed us to control, to some extent, the effect of contextual variables.

\section{Instruments}

\section{Self-Description Questionnaire: $S D Q-I$}

This multidimensional instrument (Marsh, 1988), consists of 76 items organized into eight selfconcept dimensions (general, academic [general, mathematic, verbal], social [relationships with parents and peers], and physical [physical appearance, physical capacity]), to which subjects respond on a 5-point scale. The SDQ-I is a reliable instrument with demonstrated validity (see Byrne, 1996). In the Spanish population, reliability has been shown to be high (Núñez et al., 1995), both in normal samples [general $(\alpha=0.73)$; general school $(\alpha=0.85)$; reading $(\alpha=0.86)$; mathematics $(\alpha=0.93)$; physical appearance $(\alpha=0.86)$; physical abilities $(\alpha=0.82)$; parent 
relations $(\alpha=0.76)$; peer relations $(\alpha=0.70)$; total SDQ $(\alpha=0.90)]$ and in students with LD [general ( $\alpha=0.74)$; general school $(\alpha=0.84)$; reading $(\alpha=0.92)$; mathematics $(\alpha=0.92)$; physical appearance $(\alpha=0.84)$; physical abilities $(\alpha=0.81)$; parent relations $(\alpha=0.81)$; peer relations $(\alpha=$ $0.73)$; total SDQ $(\alpha=0.92)$ ]. In addition, the Spanish version has construct validity and predictive validity for academic achievement (Núñez et al., 1995).

\section{Sydney Attribution Scale: SAS}

Developed by Relich (1983; cited in Marsh, Cairns, Relich, Barnes, \& Debus, 1984), SAS is a multidimensional scale that assesses subjects' perceptions of the causes of their academic successes and failures, adopting a dispositional viewpoint. It is made up of 24 hypothetical situations to which subjects respond on a 5-point scale. These 24 situations involve combinations of 2 academic areas (mathematics, verbal), 3 types of causes (ability, effort, external causes), and 2 hypothetical outcomes (success situations and failure situations). An example of SAS items would be:

\begin{tabular}{|c|c|c|c|c|c|}
\hline & False & & & & True \\
\hline 1. You are a good reader & 1 & 2 & 3 & 4 & 5 \\
\hline 2. You make a big effort to read well & 1 & 2 & 3 & 4 & 5 \\
\hline 3. The teacher made a mistake & 1 & 2 & 3 & 4 & 5 \\
\hline
\end{tabular}

In the present study, the academic areas were not treated separately, so that six scores were obtained: Attribution of Success to Ability (ASAB), Attribution of Success to Effort (ASEF), Attribution of Success to External Causes (ASEC), Attribution of Failure to Ability (AFAB), Attribution of Failure to Effort (AFEF), Attribution of Failure to External Causes (AFEC) (3 types of causes $\times 2$ hypothetical outcomes).

The SAS adaptation for Spanish-speaking populations has been shown to have acceptable reliability (in Spain, $\alpha=0.81$, see González-Pienda et al., 2002; and $\alpha=0.82$ in Chile, see Villalobos, González-Pienda, Núñez, \& Mújica, 1997), and construct validity and predictive validity for academic achievement (Núñez et al., 1995).

\section{Academic Goals Questionnaire: $A G Q$}

This instrument was based on an experimental questionnaire used by Hayamizu and Weiner (1991). It is made up of 20 items, eight concerning learning goals (evaluation of students' interest in learning as a priority goal), six concerning achievement goals (students' interest in obtaining a certain outcome as a priority aim), and six concerning orientation to- ward obtaining social reinforcement and acknowledgement. As in the other instruments, the subjects rated each item on a 5-point scale. Examples of the three types of goals assessed by the AGQ would be the following:

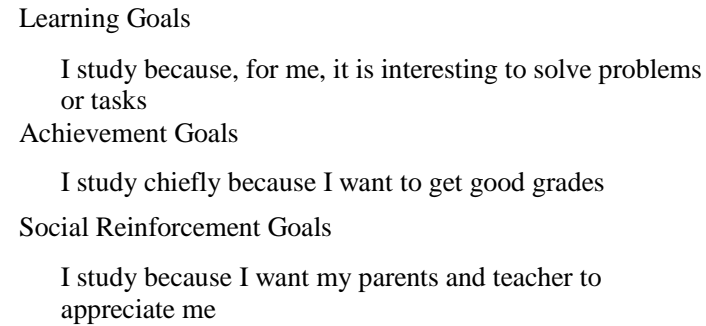

$\begin{array}{ccccc}\text { Never } & & & \text { Always } \\ 1 & 2 & 3 & 4 & 5 \\ 1 & 2 & 3 & 4 & 5 \\ 1 & 2 & 3 & 4 & 5\end{array}$


The Spanish adaptation of the AGQ has been shown to have high reliability coefficients, both for NLD students [learning goals $(\alpha=0.91)$; achievement goals $(\alpha=0.89)$; social reinforcement goals $(\alpha=0.85)$; total AGQ $(\alpha=0.92)$ ], and for LD students [learning goals $(\alpha=0.85)$; achievement goals $(\alpha=0.86)$; social reinforcement goals $(\alpha=0.83)$; total AGQ $(\alpha=0.87)$ ], as well as excellent structural validity and predictive validity for various types of learning strategies and for academic achievement (Valle et al., 2003b).

\section{General Learning Difficulties Questionnaire (GLDQ)}

This instrument was designed by the authors to obtain data about various issues theoretically related to LD. The questionnaire was completed by the teacher of each student with LD. Questions referred to: the time since the student's initial diagnosis as LD; the academic areas with significant deficits; the presence of comorbid deficits (e.g., emotional, behavioral, linguistic, or communication); relative achievement; the student's degree of involvement in school work and attitude toward failure and the student's peer relations. In Appendix 1, we provide the questionnaire items that were used in the present analyses.

\section{Procedure}

The data were gathered in two sessions in the various school centers attended by the students. Initially, we contacted representatives from the educational centers to obtain their participation in the investigation, requesting them to (1) provide data about the diagnosis of students with LD, (2) request parents' permission for their children's participation in the investigation, and (3) inform and request the teachers' collaboration to provide various data. The special assistance teachers were asked to fill in the GLDQ questionnaire. The ordinary class- room teachers filled in the GLDQ questionnaire about the students without LD (omitting the specific LD questions). The tests were administered by postgraduates with scholarships, who were collaborating with the team. The participants filled in the three questionnaires individually and without any time limit. Any doubts expressed by students about terms were cleared up.

\section{Statistical Analyses}

Various MANCOVAs were performed initially in order to compare students with and without LD on the variables studied (causal attribution, self-concept, and academic goals) and to attempt to control for age differences. In order to contrast the hypothesis of homogeneity versus heterogeneity of the group of students with LD in their typical causal attribution profile, several cluster analyses were performed, using the K-means method. Once the subgroups of students with LD were identified, MANCOVAs were conducted in which the dependent variables were the dimensions of self- concept and academic goals, and the independent variable was the subgroups of students established on the basis of their typical attributional profile and the group of NLD students. When the analysis involved more than two groups, post hoc Scheff'e tests were used to identify pairwise differences among the groups. Similarly, we performed various ANOVAs to verify differences among the attributional pro- files on several variables reported by the teacher. The effect sizes were also calculated in order to determine the portion of variance of the dependent variable that was attributable to each independent variable. Following the recommendations of authors such as Tabachnick and Fidell (1989), we report the partial squared eta $\left(\eta^{2}{ }_{p}\right)$ rather than the squared eta (see also http://www.web.uccs.edu/lbecker/Psy590/es.htm). The analysis of the partial squared eta is usually used to judge whether statistically significant differences can also be considered practically significant. According to Aron and Aron (1999), the following criteria should be used: $0.10=$ small effect size, $0.25=$ medium effect size, and $0.40=$ large effect size. 


\section{RESULTS}

\section{Preliminary Analyses}

Three initial MANCOVAs (controlling for age) were used to determine the typical pattern of group differences (LD vs. NLD) that was evident in the present sample on the major variables of interest. In general, the results point in the same direction as those obtained by a large number of researchers. The data of our study can be summed up in the following paragraphs (details of the analyses are available from the authors). In Table 1 are displayed the means and standard deviations corresponding to the groups of students with and without learning disabilities (LD and NLD, respectively).

TABLE 1. Means and Standard Deviations Corresponding to the LD-HP, LD-AP, Intact LD, and NLD Groups for SelfConcept, Academic Goals, and Attribution Patterns

\begin{tabular}{|c|c|c|c|c|c|c|c|c|}
\hline & \multicolumn{2}{|c|}{ LD-HP } & \multicolumn{2}{|c|}{ LD-AP } & \multicolumn{2}{|c|}{ Intact LD } & \multicolumn{2}{|c|}{ NLD } \\
\hline & M & SD & M & SD & M & SD & M & SD \\
\hline \multicolumn{9}{|l|}{ Self-Concept (SDQ-I Scales) } \\
\hline General $^{\mathrm{a}}$ & 20.08 & 4.57 & 22.92 & 4.47 & 21.36 & 4.73 & 23.25 & 4.24 \\
\hline General school $^{\mathrm{b}}$ & 18.73 & 5.09 & 24.29 & 6.18 & 21.24 & 6.24 & 29.00 & 6.71 \\
\hline Reading $^{\mathrm{b}}$ & 23.73 & 8.19 & 29.59 & 7.74 & 26.37 & 8.48 & 33.13 & 6.33 \\
\hline Mathematics $^{\mathrm{b}}$ & 17.57 & 6.95 & 24.73 & 8.88 & 20.80 & 8.63 & 30.76 & 8.64 \\
\hline Physical appearance $^{\mathrm{b}}$ & 24.70 & 7.36 & 27.42 & 7.02 & 25.93 & 7.32 & 27.47 & 7.99 \\
\hline Physical abilities $^{\mathrm{b}}$ & 28.82 & 7.67 & 30.21 & 7.37 & 29.45 & 7.55 & 30.70 & 6.85 \\
\hline Parent relations ${ }^{\mathrm{b}}$ & 30.04 & 6.50 & 32.80 & 6.37 & 31.29 & 6.57 & 34.05 & 5.07 \\
\hline Peer relations ${ }^{\mathrm{b}}$ & 28.04 & 5.72 & 29.89 & 5.86 & 28.87 & 5.84 & 31.07 & 5.63 \\
\hline \multicolumn{9}{|l|}{ Academic Goals (AGQ Scales) } \\
\hline Learning goals ${ }^{c}$ & 2.88 & 0.85 & 3.74 & 0.69 & 3.27 & 0.89 & 4.03 & 0.60 \\
\hline Achievement goals $^{c}$ & 2.93 & 1.09 & 3.59 & 0.92 & 3.23 & 1.07 & 3.33 & 1.14 \\
\hline Social reinforcement goals ${ }^{\mathrm{c}}$ & 3.69 & 1.04 & 4.44 & 0.67 & 4.03 & 0.97 & 4.64 & 0.48 \\
\hline \multicolumn{9}{|l|}{ Causal Attributions (SAS Scales) } \\
\hline $\begin{array}{l}\text { Attribution of Success to Ability } \\
(A S A B)^{d}\end{array}$ & 21.13 & 6.23 & 29.41 & 8.05 & 24,86 & 8.20 & 33.89 & 9.10 \\
\hline $\begin{array}{l}\text { Attribution of Success to Effort } \\
\text { (ASEF) }^{d}\end{array}$ & 28.77 & 7.62 & 38.08 & 7.90 & 32.97 & 9.01 & 40.80 & 7,26 \\
\hline $\begin{array}{l}\text { Attribution of Success to External } \\
\text { Causes (ASEC) }{ }^{\mathrm{d}}\end{array}$ & 33.33 & 5.95 & 25.98 & 5.32 & 30.02 & 6.74 & 26.27 & 7.22 \\
\hline $\begin{array}{l}\text { Attribution of Failure to Ability } \\
(\mathrm{AFAB})^{\mathrm{d}}\end{array}$ & 32.15 & 5.82 & 23.71 & 5.72 & 28.35 & 7.13 & 20.56 & 6.29 \\
\hline $\begin{array}{l}\text { Attribution of Failure to Effort } \\
(A F E F)^{d}\end{array}$ & 33.73 & 5.04 & 25.70 & 5.77 & 30.11 & 6.70 & 25.66 & 7.19 \\
\hline $\begin{array}{l}\text { Attribution of Failure to External } \\
\text { Causes (AFEC) }\end{array}$ & 27.38 & 5.84 & 24.14 & 7.04 & 25.92 & 6.59 & 23.60 & 6.47 \\
\hline
\end{tabular}

Note. LD-HP (LD students with Helplessness Profile, $n=95$ ), LD-AP (LD students with Adaptive Profile, $\mathrm{n}=78$ ), Intact LD (students with LD, $n=173$ ), NLD (students without LD, $n=172$ ).

${ }^{\mathrm{a}}$ Minimum $=6$; Maximum $=30 ;{ }^{\mathrm{b}}$ Minimum $=8 ;$ Maximum $=40 ;{ }^{\mathrm{c}}$ Minimum $=1$; Maximum $=5 ;{ }^{\mathrm{d}}$ Minimum $=10$; Maximum $=50$.

The result of the first MANCOVA revealed the existence of significant differences in attributional patterns between the two groups of students (NLD and LD), both for situations of success (Wilks' lambda $\left.=0.884, F(6,416)=9.11, p<0.001 ; \eta_{p}^{2}=0.116\right)$, and situations involving failure (Wilks' lambda $\left.=0.885, F(6,412)=8.94, p<0.001 ; \eta^{2}{ }_{p}=0.115\right)$. Specifically, the students without LD attributed their academic successes significantly more to internal factors such as ability or their own effort, and their failures significantly less to lack of ability or to lack of effort than did their class- mates with LD. With regard to self-concept, the results of the MANCOVA indicated that students with LD rated them- selves significantly lower overall (Wilks' lambda $=$ $\left.0.843, F(8,370)=8.60, p<0.001 ; \eta_{p}^{2}=0.157\right)$. Follow-up univariate ANOVAs indicated significant group differences in all subdomains except for the two physical dimensions. Lastly, the third MANCOVA revealed statistically significant differences between students with and without 
LD in the types of academic goals they pursue (Wilks' lambda $=0.835, F(3,491)=32.42, p<$ $\left.0.001 ; \eta_{p}^{2}=0.165\right)$. Students with LD as a group were significantly less oriented toward learning goals, achievement goals, and seeking social acceptance through academic involvement.

\section{Attributional Profiles in Students with LD}

Do all students with LD show similar attributional profiles for academic success and/or failure? In order to answer this question, a series of cluster analyses were performed on the data from the LD sample, using the $z$ scores obtained from the direct scores. The number of groups was fixed successively at $2,3,4,5,6$, etc. The criteria employed to select the most appropriate solution were: (1) existence of convergence after not more than 10 iterations; and (2) theoretical feasibility and psychological meaning.

Regarding the first criterion, the two- and three-subgroup solutions were most viable. Taking the second criterion into account, the two-subgroup solution was considered the most appropriate. The three-subgroup solution was similar to that of two groups, with the sole difference that one of the two groups was subdivided into two: (1) students who believe that effort is mainly responsible for their successes, but who find no justification for their failures and (2) students who believe that their successes are clearly due to their abilities and/or effort and their failures to external causes (this group coincides completely with Cluster 2 from the two-group solution). The group of individuals who felt that they could not explain their failures was made up of only 11.34 percent of students from the LD group (i.e., 11 students). Consequently, it seemed reasonable to choose the two-subgroup solution because the size of the third subgroup would be too small to allow the performance of the subsequent analyses. In the following paragraphs, the two attributional profiles are de- scribed in detail (see Figure 1).

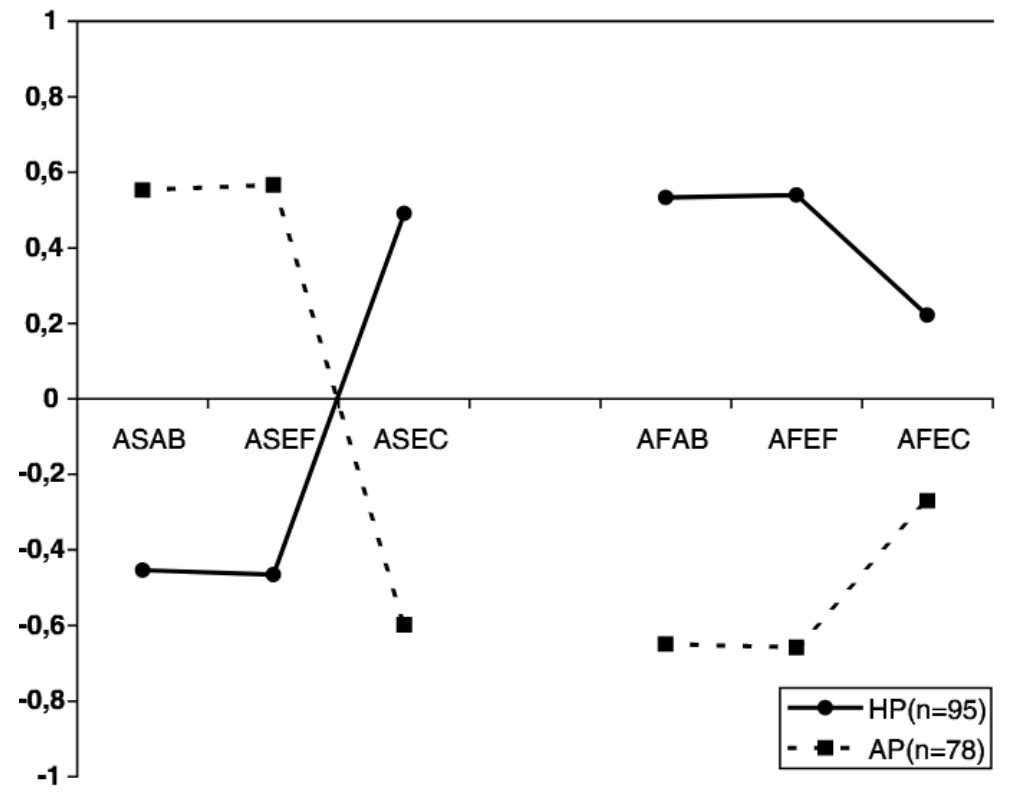

FIGURE 1. HP = Helplessness Profile (Internalization of failure/Externalization of success). AP = Adaptive Profile (Internalization of success/ Externalization of failure). ASAB = Attribution of Success to Ability. ASEF = Attribution of Success to Effort. ASEC $=$ Attribution of Success to External Causes. AFAB $=$ Attribution of Failure to Ability. AFEF $=$ Attribution of Failure to Effort. AFEC = Attribution of Failure to External Causes. 
The two-cluster solution (see Figure 1 and Table 2) showed two groups of students whose attributional profiles for success and failure are very different. Cluster $1(n=95 ; 67$ boys and 28 girls; $M_{\text {age }}=12.78, S D_{\text {age }}=1.25$ ) was characterized by students with LD who believe that their successes are mainly due to external circumstances or to circumstances having nothing to do with themselves (ASEC) and very little to do with their own skills (ASAB) or to the effort made (ASEF). In turn, they also believe that their failures are mainly caused both by their lack of ability (AFAB) and their lack of effort (AFEF), although they also consider that there are external variables that significantly influence their failures (AFEC). Summing up, there is a large group of students with LD who attribute their success chiefly to external causes and their failures chiefly to internal causes (54.9 percent of the students with LD who participated in the study). In Tables 1 and 2 and Figure 1, this group is labeled "HP" in reference to their characteristic attributional profile (Helplessness Profile).

TABLE 2. Means and Standard Deviations for the Two LD Subgroups on the Sydney Attributions Scale

\begin{tabular}{|c|c|c|c|c|}
\hline \multirow[b]{3}{*}{ SAS Subscales } & \multicolumn{4}{|c|}{ Z Scores } \\
\hline & \multicolumn{2}{|c|}{ LD-HP } & \multicolumn{2}{|c|}{ LD-AP } \\
\hline & M & SD & M & $\mathrm{SD}$ \\
\hline Attribution of Success to Ability (ASAB) & -0.454 & 0.759 & 0.553 & 0.982 \\
\hline Attribution of Success to Effort (ASEF) & -0.465 & 0.845 & 0.567 & 0.876 \\
\hline Attribution of Success to External Causes (ASEC) & 0.491 & 0.882 & -0.598 & 0.789 \\
\hline Attribution of Failure to Ability (AFAB) & 0.533 & 0.815 & -0.649 & 0.801 \\
\hline Attribution of Failure to Effort (AFEF) & 0.540 & 0.752 & -0.658 & 0.862 \\
\hline Attribution of Failure to External Causes (AFEC) & 0.222 & 0.885 & -0.270 & 1.068 \\
\hline
\end{tabular}

Note. LD-HP $=$ LD Students with Helplessness Profile $(n=95)$. LD-AP $=$ LD Students with Adaptive Profile $(n=78)$, SAS (Sydney Attribution Scale).

Cluster $2\left(n=78 ; 50\right.$ boys and 28 girls; $\left.M_{\text {age }}=11.68, S D_{\text {age }}=1.52\right)$ was characterized by students with LD who believe that their successes are partially due to external causes (ASEC) but importantly due to their abilities (ASAB) and, above all, to the effort made (ASEF). In turn, although they do not seem certain which variable(s) are responsible for their failures, they do not consider them to be caused by their lack of ability (AFAB) or their lack of effort (AFEF). They consider the concurrence of external variables to be the main cause of their failures (AFEC). Summing up, there is a group of students with LD (45.1 percent) who attribute their success chiefly to internal causes (ability and effort) and their failures predominantly to external causes. In Tables 1 and 2 and in Figure 1, this group is labeled "AP" in reference to their characteristic attributional profile (Adaptive Profile).

As an initial means of verifying the two-cluster solution, a MANOVA was performed to determine whether the two profiles were statistically different on the six dimensions that make up these profiles (ASAB, ASEF, ASEC, AFAB, AFEF, AFEC). In accordance with a simple visual inspection of Figure 1, the data provided by the MANOVA indicated that the two subgroups of students account for both success and failure in significantly different ways (Wilks' lambda = $\left.0.335, F(6,166)=54.833, p<0.001 ; \eta_{p}^{2}=0.665\right)$. Regarding the specific dimensions that make up the profiles, significant differences between the groups were obtained for all six attributional variables: Attribution of Success to Ability (ASAB), $F(1,171)=57.94, p<0.001, \eta_{p}^{2}=0.253$; Attribution of Success to Effort (ASEF), $F(1,171)=61.82, p<0.001, \eta_{p}^{2}=0.266$; Attribution of Success to External Causes (ASEC), $F(1,171)=71.75, p<0.001, \eta_{p}^{2}=0.296$; Attribution of Failure to Ability (AFAB), $F(1,171)=91.40, p<0.001, \eta_{p}^{2}=0.348$; Attribution of Failure to Effort (AFEF), $F(1,171)=95.21, p<0.001, \eta^{2}=0.358$; and Attribution of Failure to External Causes (AFEC), $F(1,171)=10.99, p=0.001, \eta_{p}^{2}=0.060$. The medium effect sizes $\left(\eta_{p}^{2}\right)$ suggest that the differences between the two profiles (AP, HP) are not only statistically reliable but also of practical significance because they explain a large quantity of variance of the six dimensions of the SAS (except for AFEC). 
No statistically significant differences in intellectual skills (WISC-R) were obtained between the two subgroups of students with LD, either for general ability $\left(M_{L D-A P}=89.32, S D_{L D-A P}=7.35\right.$; $\left.M_{L D-H P}=88.32, S D_{L D-H P}=6.32 ; F(1,171)=0.913 ; p=0.341\right)$, or for verbal ability $\left(M_{L D-A P}=\right.$ $\left.84.95, S D_{L D-A P}=7.73 ; M_{L D-H P}=83.55, S D_{L D-H P}=7.82 ; F(1,171)=1.390 ; p=0.240\right)$ or performance ability $\left(M_{L D-A P}=94.44, S D_{L D-A P}=9.07 ; M_{L D-H P}=93.65, S D_{L D-H P}=7.48 ; F(1,171)\right.$ $=0.400 ; p=0.528)$.

In order to describe in more detail each of these two pro- files, we performed several ANOVAs, using as dependent variables several variables reported in the General Learning Difficulties Questionnaire. These variables may be particularly relevant for making inferences about why a particular attributional profile is evident. The variables considered were: time since diagnosis; academic achievement; degree of persistence when faced with failure, feelings associated with the individual's difficulties, and peers' behavior toward the students.

Regarding teachers' ratings of the time since diagnosis (computed in years: 1 to 5), the results of the ANOVA revealed no significant differences between the two groups of students, (LD-AP: $M=2.74, S D=1.62) ;(\mathrm{LD}-\mathrm{HP}: M=2.91, S D=1.54) ; F(1,84)=0.267, p=0.607$.

Regarding "achievement in the academic areas in which a significant delay is observed," the data revealed statistically significant differences, with the students who had an adaptive attributional profile showing higher achievement $\left(M_{L D-A P}=2.76, S D_{L D-A P}=0.90 ; M_{L D-H P}=2.47\right.$, $\left.S D_{L D-H P}=0.86 ; F[1,170]=4.572, p=0.034\right)$. Similarly, in the academic areas in which no delay or only slight delay was observed, there were significant differences in favor of the LD-AP group $\left(M_{L D-A P}=1.38, S D_{L D-A P}=0.61 ; M_{L D-H P}=1.20, S D_{L D-H P}=0.44 ; F[1,167]=4.872, p=0.029\right)$.

The data reported by the teachers revealed statistically significant differences between the two groups of students in the degree of persistence following failure situations $\left(M_{L D-A P}=2.46\right.$, $\left.S D_{L D-A P}=0.64 ; M_{L D-H P}=1.92, S D_{L D-H P}=0.63 ; F[1,171]=31.749, p<0.001\right)$, indicating that students in the LD-HP subgroup desisted following failure much more easily than did their classmates with an adaptive attributional profile (LD-AP). In accordance with the pre- ceding results, the data also showed that students with the LD-HP profile, compared to students with an adaptive pro- file, felt significantly "less capable than" and "inferior to" others $\left(M_{L D-A P}=3.79\right.$, $\left.S D_{L D-A P}=0.92 ; M_{L D-H P}=2.89, S D_{L D-H P}=1.00 ; F[1,170]=36.482, p<0.001\right)$. Lastly, regarding peers' behavior toward students with $L D$, the results revealed no statistically significant differences $\left(M_{L D-A P}=2.89, S D_{L D-A P}=0.42 ; M_{L D-H P}=2.77, S D_{L D-H P}=0.59 ; F[1,168]=2.545, p\right.$ $=0.113$ ).

\section{Differences in Self-Concept and Academic Goals Among Students with LD-HP, LD-AP, and NLD Students}

In this last section, we consider the hypothesis that the differences in self-concept and motivation between students with and without LD will be significant for the LD-HP group, but not for the LD-AP group. A MANCOVA was performed with an independent variable consisting of three levels (NLD students, LD-HP students, and LD-AP students), and with 11 dependent variables ( 8 self-concept dimensions measured by the SDQ and 3 kinds of academic goals obtained by means of the AGQ), using age as a covariate. The corresponding means and standard deviations are presented in Table 1.

Age had a statistically significant effect on the set of dependent variables (Wilks' lambda $=$ $\left.0.873, F(11,331)=4.377, p<0.001 ; \eta_{p}^{2}=0.127\right)$. The effect of age was observed on the three academic dimensions of self-concept (general mathematical, and reading), on the physical ability dimension, and also on the three types of academic goals. In general, as students become older, their self-image as students becomes more negative, as does their degree of motivation toward schoolwork. Taking age into account, the multivariate test yielded a statistically significant effect of group on the 11 dependent variables, taken conjointly (Wilks' lambda $=0.644$, with $F(22,662$ ) $\left.=7.393, p<0.001 ; \eta_{p}^{2}=0.208\right)$. The results of follow-up ANOVAs for each of the dependent variables indicated that there were statistically significant differences among the three levels of the group variable (LD-HP, LD-AP, NLD) for all of the 11 dependent variables except the "physical ability" and "physical appearance" [general self-concept $\left(F(2,341)=9.18, p<0.001 ; \eta^{2}=0.051\right)$; 
academic self-concept $\left(F(2,341)=36.83, p<0.001 ; \eta_{p}^{2}=0.178\right)$; reading self-concept $(F(2,341)$ $\left.=23.57, p<0.001 ; \eta_{p}^{2}=0.121\right)$; mathematics self-concept $\left(F(2,341)=30.78, p<0.001 ; \eta_{p}^{2}=\right.$ $0.153)$; parent relations $\left(F(2,341)=8.66, p<0.001 ; \eta_{p}^{2}=0.048\right)$; peer relations $(F(2,341)=5.04$, $\left.p=0.007 ; \eta_{p}^{2}=0.029\right)$; learning goals $\left(F(2,341)=34.90, p<0.001 ; \eta_{p}^{2}=0.170\right)$; Social reinforcement goals $\left(F(2,341)=23.01, p<0.001 ; \eta_{p}^{2}=0.119\right)$; and achievement goals $(F(2,341)$ $\left.\left.=6.02, p=0.003 ; \eta_{p}^{2}=0.034\right)\right]$.

Scheffée's post hoc procedure showed that for all the dependent variables there were statistically significant differences between the groups of LD-HP students and their NLD peers, and these differences consistently favored the NLD group. On the other hand, there were no statistically significant differences between the students with LD who had an adaptive profile (LD-AP Group) and the NLD students, with the exception of the academic dimensions of selfconcept (general school, reading, and mathematics) and learning goals. Lastly, there were statistically significant differences between the two groups of LD students (LD-HP and LD-AP) for all the dependent variables, except for physical abilities and peer relations. These differences consistently favored the LD-AP students.

\section{DISCUSSION}

The results of our preliminary analyses of the data coincided with those provided by a large number of previous studies in that students with LD had a significantly more negative self- image than their peers without LD, both at an academic level and at the level of general self-concept, and even regarding other facets of themselves (social, family). However, in our subsequent analyses, data were obtained that provide support for the hypothesis that students with LD are not homogeneous with respect to their attributions for academic successes and failures. Specifically, the cluster analysis performed yields two subgroups of students with LD that are significantly different in their attributional profile: students with an adaptive profile and students with a helplessness profile. In addition to their particular pattern of attributing causes to successes and failures, we found that students with a helplessness attributional profile, compared to those who develop an adaptive attributional profile, perceived themselves to be less capable of learning and less persistent following situations involving failure. In addition, their teachers rated their achievement as lower, both in the academic areas that do not make up the nucleus of their deficits and in their specific area(s) of deficit. However, no statistically significant differences were found between the two groups of students (LD-AP, LD-HP) in intellectual skills. Contrary to our expectations, however, the time interval since the student was diagnosed LD did not seem to be a determinant in the development of a specific kind of attributional profile.

The results of our preliminary analyses were somewhat modified when repeating the MANCOVAs differentiating students with LD according to their attributional profile. Specifically, there were large differences when comparing students with LD who have a maladaptive profile of help- lessness (LD-HP) with their NLD peers. In contrast, there were no significant differences, except for the academic di- mension, between students with and without LD, if the for- mer are characterized by an adaptive attributional profile (LD-AP). Even so, in this study, statistically significant dif- ferences were obtained in the academic dimensions between students with and without LD (although in the case of the LD group with an adaptive attributional profile, these differ- ences were lower than with regard to the helplessness profile group).

Regarding the issue of motivation, our results indicated the existence of very large group differences between LD- HP students and NLD students regarding the three types of academic goals. On the other hand, as in the case of self- concept, no statistically significant differences were observed between the LD-AP group and the NLD group. This result is in accordance with the findings of authors such as Hagen and Weinstein (1995), Harackiewicz and Elliot (1993), Pintrich and DeGroot (1990), and Wentzel (1999), among others, who reported that students' motivation toward academic tasks is closely related to their beliefs about their competence and their self-efficacy expectations (Valle et al., 2003b). On the other hand, as also regards motivation, we obtained evidence that students with LD-HP show significantly less interest in winning significant others' approval and social reinforcement (as a consequence of their academic performance) than do their counterparts with LD-AP and NLD. The lower tendency to win social acknowledgement could be explained by these students' perceptions of other people's negative 
expectations of their learning, especially their parents and teachers (see Meltzer et al., 1998), or their peers (as indicated by our data). Moreover, these students' lower interest in winning others' approval may be due to the attributional profile found by Settle and Milich (1999) concerning interpersonal relationships (they blame themselves and excuse others for the deterioration of interpersonal relationships). Lastly, we also obtained significant differences in achievement goals, although they were small. Nonetheless, our data seem to indicate that students with LD who have an adaptive attributional profile show higher levels of achievement goals, even higher than the NLD students (see Table 1). These results seem to indicate that, at least, these students with LD (LD-AP) present adaptive achievement-related motivation.

To sum up, the data provided by our investigation indicate that although a high percentage of students with LD develop an attributional profile of helplessness (54.9 percent in this study), an important number of students with LD develop an adaptive attributional profile (45.1 percent). In line with the results of Licht and Kistner (1986), the LD-HP students who participated in this study, compared with the LD-AP group, are characterized by having less confidence in their ability to cope with schoolwork (despite there being no significant differences in their intellectual abilities), a poorer self-concept as students (that is generalized to the social and family areas as well as at a general level), less motivation in any of the three areas assessed (toward learning, achievement, and gaining social approval through academic involvement), less persistence following failure, and poorer academic achievement, both in the areas related to their specific deficits and in other curricular areas. Other researchers have also found that these children generalize their beliefs (low self-efficacy expectations, low self-esteem, poor motivation) to academic tasks or areas where they had not failed previously, or to those tasks where they are really capable (Montague \& Applegate, 2001). These affective-motivational conditions of the LD-HP group, in turn, become an additional handicap to these children's already reduced personal circumstances when they face the next learning event (Garcia \& Pintrich, 1994; Marsh et al., 1984; Martín, Marsh, Williamson, \& Debus, 2003; Núñez, 2004; Rodríguez, Cabanach, Valle, Núñez, \& González-Pienda, 2004; Urdan \& Baumeister, 2001; van Laar, 2000; Weiner, 2000).

\section{Implications For Research and Practice}

Currently, intervention programs focus more on the attribution to deficient quality of effort rather than to quantity. These programs attempt to make students understand that their failures are due more to the inadequate use (or lack of use) of cognitive strategies than to lack of ability. Such training stimulates in students the development of self-confidence in their ability, as well as feelings of autonomy and control, and these beliefs enhance the process of causal attribution, learning, and academic achievement (Borkowski \& Thorpe, 1994; Zimmerman, Bonner, \& Kovach, 1996). Students who experience success instead of failure will have a more positive selfconcept, and more trust in their ability, and they will assume more responsibility for their performance and display higher levels of engagement, effort, and persistence. All of this will lead to a more positive attitude toward learning and, subsequently, to higher academic achievement (Valle et al., 2003a).

However, the success of a particular intervention program depends not only on the coherence of the theoretical model but also on the existence of important individual differences in the students with LD who participate in the experience. The results obtained in this investigation reveal the existence of two very distinct attributional profiles in students with LD. When commenting on them, we have indicated the relation of these profiles to self-concept, motivation, and the use of defensive strategies. Consequently, along the lines of Elbaum and Vaughn (2003), the elaboration of an intervention program should take into account these initial individual differences because they can definitely influence the success or failure of the intervention. In addition, as observed above, the development of a specific attributional profile is associated with significant differences in learning-relevant variables such as perception of incapacity, academic self-concept, academic motivation, level of effort or persistence when faced with failure and, logically, very different levels of academic achievement.

In general, although the results of this study seem consistent, some important limitations advise one to interpret them cautiously. First, in this study, the sample was obtained by means of a diagnosis carried out by the counselors in the various centers that participated in the investigation, 
which can lead to extraneous variables in the identification of the sample. Second, the information about some of the important variables in this study was obtained by means of a questionnaire filled in by the teachers, which limits its validity, and the measuring scales are ordinal. Third, given the correlational nature of the study, it is not possible to infer causality on the basis of the data gathered. However, with a view to designing an intervention program for the classroom, we should determine the specific relationship between each of these variables. For example, although we currently know the reciprocal influence between the processes of causal attribution, self-concept, and achievement (Marsh, Byrne, \& Yeung, 1999; Marsh et al., 1984; Núñez et al., 1998), we still do not know the specific reasons why some students lend more weight to some of these variables compared to the rest in the determination of their behavior in academic learning situations.

In future research, in which the main variable should be self-concept, investigators should consider the use of longitudinal designs, with several repeated measures, taken at different times, of the variables included in the design, in order to go beyond mere description and reach acceptable explanatory levels. This type of design, together with the use of the appropriate data analysis techniques (e.g., analysis of covariance structures), could be adequate to study which conditions (of the family, school, and personal setting) lead students with LD to adopt a specific kind of attributional pro-file and how this influences some of the personal variables, such as those studied herein, so that it significantly conditions learning and academic achievement. This information would be very valuable to plan interventions to modify these cognitive, affective, and motivational conditions that so incapacitate many students with LD.

\section{ACKNOWLEDGMENT}

We wish to express our gratitude to the anonymous reviewers for their valuable comments on the earlier version of this manuscript; moreover we wish to thank Dr. C. Addison Stone for his vital suggestions and guidance from first version to the actual form of the manuscript.

\section{REFERENCES}

Ames, C. (1992). Classrooms: Goals, structures and student motivation. Journal of Educational Psychology, 84, 261-271.

Aron, A., \& Aron, E. N. (1999). Statistics for psychology. Upper Saddle River , NJ : Prentice Hall.

Bakker, J. T. A., \& Bosman, A. M. T. (2003). Self-image and peer acceptance of Dutch students in regular and special education. Learning Disability Quarterly, 26, 5-14.

Bear, G. G., \& Minke, K. M. (1996). Positive bias in the maintenance of self-worth among children with LD. Learning Disability Quarterly, 19, 23-32.

Bear, G. G., Clever, A., \& Proctor, W. A. (1991). Self-perceptions of non-handicapped children and children with learning disabilities in integrated classes. Journal of Special Education, 24, 409-426.

Bear, G. G., Juvonen, J., \& McInerney, F. (1993). Self-perceptions and peer relations of boys with and without learning disabilities in an integrated setting: A longitudinal study. Learning Disability Quarterly, 16, 127-136.

Bear, G. G., Minke, K. M., Griffin, Sh. M., \& Deemer, S. A. (1998). Achievement-related perceptions of children with learning disabilities and normal achievement: Group and developmental differences. Journal of Learning Disabilities, 31, 91-104.

Borkowski, J. G., \& Thorpe, P. K. (1994). Self-regulation and motivation: A life-span perspective on underachievement. In D. H.Schunk \& B. J.Zimmerman (Eds.), Selfregulation of learning and performance. Issues and educational applications (pp. 45-74). Hillsdale, NJ : Erlbaum.

Byrne, B. M. (1996). Measuring self-concept across the life span: Issues and instrumentation. Washington, DC : American Psychological Association.

Chapman, J. W. (1988). Cognitive-motivational characteristics and academic achievement of learning disabled children: A longitudinal study. Journal of Educational Psychology, 80, 357-365.

Covington, M. V. (1998). The will to learn. A guide for motivating young people. Cambridge , UK : Cambridge University Press.

Durrant, J. E. (1993). Attributions for achievement outcomes among behavioral subgroups of children with learning disabilities. The Journal of Special Education, 27, 306-320. 
Dweck, C. S., Chiu, C., \& Hong, Y. (1995). Implicit theories: Elaboration and extension of the model. Psychological Inquiry, 6, 322-333.

Dyson, L. L. (2003). Children with learning disabilities within the family context: A comparison with siblings in global self-concept, academic self-perception, and social competence. Learning Disabilities Research \& Practice, 18, 1-9.

Elbaum, B. (2002). The self-concept of students with learning disabilities: A meta-analysis of comparisons across different placements. Learning Disabilities Research \& Practice, 17, 216-226.

Elbaum, B., \& Vaughn, Sh. (2003). For which students with learning disabilities are selfconcept interventions effective? Journal of Learning Disabilities, 36, 101-108.

Gans, A. M., Kenny, M. C., \& Ghany, D. L. (2003). Comparing the self-concept of students with and without learning disabilities. Journal of Learning Disabilities, 36, 287-295.

Garcia, T., \& Pintrich, P. R. (1994). Regulating motivation and cognition in the classroom: The role of self-schemas and self-regulatory strategies. In D. H.Schunk \& B.

J.Zimmerman (Eds.), Self-regulation of learning and performance. Issues and educational applications (pp. 127-154). Hillsdale, NJ : Erlbaum.

González-Pienda, J. A., Núñez, J. C., González-Pumariega, S., Alvarez, L., Roces, C., García, M., et al. (2000). Self-concept, causal attribution process and academic goals in children with and without learning disabilities. Psicothema, 12, 548-556.

González-Pienda, J. A., Núñez, J. C., González-Pumariega, S., Alvarez, L., Roces, C., \& García, M. (2002). A structural equation model of parental involvement, motivational and aptitudinal characteristics, and academic achievement. Journal of Experimental Education, 70(3), 257-287.

Gresham, F. M., \& MacMillan, D. L. (1997). Social competence and affective characteristics of students with mild disabilities. Review of Educational Research, 67, 377-415.

Grolnick, W. S., \& Ryan, R. M. (1990). Self perceptions, motivation, and adjustment in children with learning disabilities: A multiple group comparison study. Journal of Learning Disabilities, 23, 177-184.

Hagen, A. S., \& Weinstein, C. E. (1995). Achievement goals, self-regulated learning, and the role of classroom context. In P. R.Pintrich (Ed.), Understanding self-regulated learning (pp. 43-56). San Francisco : Jossey-Bass.

Harackiewicz, J., \& Elliot, A. J. (1993). Achievement goals and intrinsic motivation. Journal of Personality and Social Psychology, 65, 904-915.

Harter, S., Whitesell, N. R., \& Junkin, L. J. (1998). Similarities and differences in domainspecific and global self evaluations of learning-disabled, behaviorally disordered, and normally achieving adolescents. American Education Research Journal, 35, 653-680.

Hayamizu, T., \& Weiner, B. (1991). A test of Dweck's model of achievement goals as related to perceptions of ability. Journal of Experimental Education, 59, 226-234.

Jakobsen, G., Lowery, B. Y., \& Ducette, J. (1986). Attributions of learning disabled children. Journal of Educational Psychology, 78, 59-64.

Kirk, S. A., \& Gallagher, J. J. (1986). Educating exceptional children. Boston : Houghton Mifflin.

Kloomok, S., \& Cosden, M. (1994). Self-concept in children with learning disabilities: The relationship between global self-concept, academic "discounting," nonacademic selfconcept, and perceived social support. Learning Disability Quarterly, 17, 140-153.

Licht, B. G., \& Kistner, J. A. (1986). Motivational problems of learning disabled children: Individual differences and their implications for treatment. In J. K.Torgesen \& B. Y. L.Wong (Eds.), Psychoeducational and educational perspectives on learning disabilities (pp. 225-255). Orlando, FL : Academic Press.

Marsh, H. W. (1988). Self-Description Questionnaire, I. San Antonio, TX : The Psychological Corporation.

Marsh, H. W., Byrne, B., \& Yeung, A. S. (1999). Causal ordering of academic self-concept and achievement: Reanalysis of a pioneering study and revised recommendations. Educational Psychologist, 34(3), 155-167.

Marsh, H. W., Cairns, L., Relich, J., Barnes, J., \& Debus, R. (1984). The relationship between dimensions of self-attribution and dimensions of self-concept. Journal of Educational Psychology, 76, 3-32

Martin, A. J., Marsh, H. W., Williamson, A., \& Debus, R. L. (2003). Self-handicapping, defensive pessimism, and goal orientation: A qualitative study of university students. Journal of Educational Psychology, 95, 617-628.

McPhail, J. C., \& Stone, C. A. (1995). The self-concept of adolescents with learning disabilities: A review of literature and a call for theoretical elaboration. Advances in Learning and Behavioral Disabilities, 9, 193-226.

Meltzer, L. J., \& Montague, M. (2001). Strategic learning in students with learning disabilities: What have we learned? In D.Hallahan \& B. K.Keogh (Eds.), Research and global perspectives in learning disabilities (pp. 11-130). Mahwah, NJ : Erlbaum. 
Meltzer, L. J., Roditi, B., Houser, R. F., \& Perlman, M. (1998). Perceptions of academic strategies and competence in students with learning disabilities. Journal of Learning Disabilities, 31, 437-451.

Montague, M., \& Applegate, B. (2001). Middle school students' perceptions, persistence, and performance in mathematical problem solving. Learning Disability Quarterly, 23, 215228.

Montague, M., \& Van Garderen, D. (2003). A cross-sectional study of mathematics achievement, estimation skills, and academic self-perception in students of varying ability. Journal of Learning Disabilities, 36, 437-448.

Montgomery, M. S. (1994). Self-concept and children with learning disabilities: Observed child concordance across six context-dependent domains. Journal of Learning Disabilities, 27, 254-262.

Nowicki, E. A. (2003). A meta-analysis of the social competence of children with learning disabilities compared to classmates of low and average to high achievement. Learning Disability Quarterly, 26, 171-188.

Núñez, J. C. (2004). Perfiles socio-emocionales en alumnos con dificultades de aprendizaje[Social-emotional profiles in students with learning difficulties]. Paper presented at the Vth Winter Courses of the University of Valladolid (Reconceptualization of learning difficulties). Valladolid, Spain : University of Valladolid .

Núñez, J. C., González-Pumariega, S., \& González-Pienda, J. A. (1995). Self-concept in children with and without learning disabilities. Psicothema, 7, 587-604.

Núñez, J. C., González-Pienda, J. A., García, M., González-Pumariega, S., Roces, C., Cabanach, R. G., et al. (1998). Causal relationship between the self-concept and the academic achievement. 6th Workshop on Achievement and Task Motivation. Thessaloniki, Greece .

Núñez, J. C., González-Pienda, J. A., Roces, C., González-Pumariega, S., Alvarez, L., González, P., et al. (2002). Do all the students with learning disabilities show the same attributional profile? 8th International Conference on Motivation/Workshop on Achievement and Task Motivation (WATM). Moscow .

Pintrich, P. R. (2000). Educational Psychology at the millennium: A look back and a look forward. Educational Psychologist, 35, 221-226.

Pintrich, P. R., \& DeGroot, E. V. (1990). Motivational and self-regulated learning components of classroom academic performance. Journal of Educational Psychology, 22, $33-40$.

Pintrich, P. R., Anderman, E. M., \& Klobucar, C. H. (1994). Intraindividual differences in motivation and cognition in students with learning disabilities. Journal of Learning Disabilities, 27, 360-370.

Priel, B., \& Leshem, T. (1990). Self-perceptions of first- and second-grade children with learning disabilities. Journal of Learning Disabilities, 23, 637-642.

Rodríguez, S., Cabanach, R. G., Valle, A., Núñez, J. C., \& González-Pienda, J. A. (2004). Differences in the use of self-handicapping and defensive pessimism and its relation with achievement goals, self-esteem, self-regulated learning strategies. Psicothema, 16(4), 626-632.

Rogers, H., \& Saklofske, D. H. (1985). Self-concepts, locus of control and performance expectations of learning disabled children. Journal of Learning Disabilities, 18, 273-278.

Rosenberg, M. S., Bott, D., Majsterek, D., Chiang, B., Gartland, D., Wensson, C., et al. (1993). Minimum for the description of participants in learning disabilities research. Journal of Learning Disabilities, 26, 210-213.

Sabornie, E. (1994). Social-affective characteristics in early adolescents identified as learning disabled and nondisabled. Learning Disability Quarterly, 17, 268-279.

Schuh, K. L. (2003). Knowledge construction in the learner-centered classroom. Journal of Educational Psychology, 95, 426-442.

Seligman, M. E. P. (1990). Learned optimism: How to change your mind and your life. London : Pocket Books.

Settle, Sh. A., \& Milich, R. (1999). Social persistence following failure in boys and girls with LD. Journal of Learning Disabilities, 32, 201-212.

Smiley, P. A., \& Dweck, C. S. (1994). Individual differences in achievement goals among young children. Child Development, 65, 1723-1743.

Stone, C. A. (2002). Engaging students with learning disabilities in instructional discourse: A commentary on the REACH papers. Learning Disabilities Research \& Practice, 17, 201203.

Stone, C. A., \& May, A. L. (2002). The accuracy of academic self-evaluations in adolescents with learning disabilities. Journal of Learning Disabilities, 35, 370-383.

Tabachnick, B. G., \& Fidell, L. S. (1989). Using multivariate statistics (2nd ed.). New York : Harper \& Row.

Urdan, T. C., \& Baumeister, R. F. (2001). Academic self-handicapping: What we know, what more there is to learn. Educational Psychology Review, 2, 115-138. 
Valas, H. (1999). Students with learning disabilities and low-achieving students: Peer acceptance, loneliness, self-esteem, and depression. Social Psychology of Education, 3, 173-192.

Valle, A., Cabanach, R., Núñez, J. C., González-Pienda, J. A., Rodríguez, S., \& Piñeiro, I. (2003a). Cognitive, motivational, and volitional dimensions of learning: An empirical test of a hypothetical model. Research in Higher Education, 44, 557-580.

Valle, A., Cabanach, R., Núñez, J. C., González-Pienda, J. A., Rodríguez, S., \& Piñeiro, I. (2003b). Multiple goals, motivation and academic learning. British Journal of Educational Psychology, 73, 71-87.

Van Laar, C. (2000). The paradox of low academic achievement but high self-esteem in African- American students: An attributional account. Educational Psychology Review, $12,33-61$.

Vaughn, S., Elbaum, B. E., Schumm, J. S., \& Hughes, M. T. (1998). Social outcomes for students with and without learning disabilities in inclusive classrooms. Journal of Learning Disabilities, 31, 428-436.

Vaughn, S., Haager, D., Hogan, A., \& Kouzekanani, K. (1992). Self-concept and peer acceptance in students with learning disabilities: A four- to five-year prospective study. Journal of Educational Psychology, 84, 43-50.

Villalobos, M. V., González-Pienda, J. A., Núñez, J. C., \& Mújica, A. D. (1997). Sydney Attribution Scale: Facture structure and psychometric properties in Chilean students. Ist Portuguese-Spanish Congress of Educational Psychology. Coimbra, Portugal : Apport.

Weiner, B. (2000). Intrapersonal and interpersonal theories of motivation from an attributional perspective. Educational Psychology Review, 12, 1-14.

Wentzel, K. R. (1999). Social-motivational processes and interpersonal relationships: Implications for understanding motivation at school. Journal of Educational Psychology, 91, 76-97.

Zimmerman, B. J., Bonner, S., \& Kovach, R. (1996). Developing self-regulated learners. Beyond achievement to self-efficacy. Washington, DC : American Psychological Association. 